\title{
Isolated Extrapulmonary Thoracic Hydatid Cyst with Subcutaneous Extension - A Rare Entity
}

\author{
Sarvesh Sharma ${ }^{1}$, Ravisagar Patel ${ }^{2}$, Abhinav Singh $^{2}$, Rajendra Mohan Mathur ${ }^{3}$ \\ ${ }^{I}$ RESIDENT M.Ch CTVS, Department of cardiothoracic and vascular surgery, Jaipur, India \\ ${ }^{2}$ RESIDENT M.Ch CTVS, Department of cardiothoracic and vascular surgery, Jaipur, India \\ ${ }^{3}$ Professor and Head of the Department of cardiothoracic and vascular surgery, Jaipur, India
}

\begin{abstract}
Hydatid disease is a parasitic infestation, the pulmonary variant, caused by Echinococcus multilocularis is less common and the extra pulmonary thoracic variant even rare. We report a case of 52 year old female who underwent complete surgical excision of isolated right sided thoracic extrapulmonary hydatid cyst with subcutaneous extension. The postoperative period was uneventful. She was discharged on the $6^{\text {th }}$ post op day and is in regular follow up and doing well.
\end{abstract}

\section{Case Report}

A 52 year multigravida, normotensive, nondiabetic, female presented with complains of cough, shortness of breath, associated with right sided chest heaviness and pain for 4 years. A non-tender gradually progressive lump of size $5 \times 3 \mathrm{~cm}$ was present over the the right infraclavicular region lateral to midclavicular line upto anterior axillary line. There was no history of haemoptysis or tuberculosis. The blood investigation showed eosinophilia, with ELISA-Hydatid serology positive. X-ray chest showed a large single rounded opacity over the right upper and middle lung field[figure 1]. CT Scan showed a large lobulated mass of size $11.6 \times 7.7 \mathrm{~cm}$ arising in the right upper chest with extension into the anterolateral chestwall overlying $2^{\text {nd }}, 3^{\text {rd }}, 4^{\text {th }}$ ribs[figure 2,3]. The underlying lung parenchyma was only abutted but not infilterated. The pulmonary function test showed FEV1 83\% predicted and FEV1/FVC 110\% predicted.

The patient underwent Right thoracotomy with excision of the extrapulmonary hydatid cyst. She did well in the postoperative period and was discharged on the $6^{\text {th }}$ postoperative day. The biopsy confirmed the diagnosis of hydatid cyst.

\section{Discussion}

Hydatid cyst disease is a zoonotic disease caused by tapeworm (genus Echinococcus). The most common form found in humans is cystic echinococcosis (also known as unilocular echinococcosis), caused by Echinococcus granulosus. The second most common form is alveolar echinococcosis which is caused by Echinococcus multilocularis and the third is polycystic echinococcosis caused by Echinococcus vogeli and rarely by Echinococcus oligarthrus ${ }^{[1]}$. The endemic areas are the Mediterranean countries, the Middle East, the southern part of South America, Iceland, Australia, New Zealand, and southern parts of Africa. Infestation by hydatid disease in humans most commonly occurs in the liver (55-70\%) followed by the lung $(18-35 \%)$, the two organs can be affected simultaneously in about $5-13 \%$ of cases ${ }^{[2]}$. Isolated pulmonary hydatid cysts are uncommon. The incidence of pulmonary hydatid cysts has been varyingly reported to be between 10 and $40 \%$ among patients with hydatid disease ${ }^{[3]}$. Intrathoracic but extrapleural hydatid cysts are still rarer and can be located in the fissures, pleural cavity, chest wall, mediastinum, myocardium, and diaphragm. Though daughter cysts in pleura and pleural complications of primary pulmonary hydatid disease have been reported, primary extra-pulmonary hydatids are extremely rar ${ }^{[5,6]}$. The route of pulmonary infestation can be Intestinal, lymphatics, venal-venous anastomosis in the liver and the space of Retzius.The clinical features of cystic hydatidosis are highly variable and depend on the size, number of cyst, location in the thorax, and their interaction with the surrounding organs. They usually present with chronic cough, shortness of breath and chest pain because of the compression of the trachea-bronchial tree and reduction of the lung volume. Mediastinal cysts may cause compression of the major vessels and trachea. They may present with complications like rupture and spread of protoscolices and larval material into pleural cavity or blood vessels, bacterial infection of cysts. Immunologic reactions such as asthma, anaphylaxis, or membranous nephropathy secondary to release of antigenic material are not uncommon.

\section{Diagnosis}

Blood investigations : Blood eosinophil count, ELISA ( high specitiy ), Indirect hemagglutination tests, Skin tests, complement fixation can be used for diagnostic purposes, but one must remain aware of their tendency toward false-positive results and are not used routinely. 
Imaging

X-ray is supportive and CT scan is the main diagnostic tool for thoracic pathologies. CT scan provides information about the morphological characters of the cysts and location ${ }^{[7,8]}$. On the basis of density hydatid cysts of the lungs can be classified as simple cysts, complicated cysts, and ruptured cysts, including cystobronchial communication. Inverse Crescent sign, Signet ring sign, high CT density, and thick wall should be recognized as features of pulmonary hydatid cyst The germinative membrane may be visible by CT.

MRI may have advantages over CT scanning in the evaluation of postsurgical residual lesions and in recurrences. Calcification can occur in pulmonary or mediastinal hydatid cysts.

Depending upon the location of the cyst in the thorax various surgical approaches like thoracotomy, sternotomy, have been reported for extrapulmonary and mediastinal hydatidosis. Similarly pulmonary and hepatic cysts can be managed simultaneously through the thoracic route. Though the more radical total pericystectomy has been described by some authors, a simple cystectomy will suffice in most instances with comparable results ${ }^{[9]}$.

The basic principles of hydatid cyst surgery should always be followed i.e. Complete removal of the cyst /cyst wall including the germinal membrane. Utmost care should be taken to avoid any accidental spilling of hydatid fluid into the operative field. The surrounding areas of the cyst should be packed with sponges. At the time of opening of parietal pleura care should be taken to avoid accidental incision over the cyst, as the intrapleural cysts lies immediately below the parietal pleura. A careful dissection of the wall of the cyst is demanded without injuring the visceral pleura which may lead to postoperative persistent air leak and bronchopleural fistula. Video-Assisted Thoracic Surgery (VATS) are the recent treatment modalities for hydatid cyst ${ }^{[10]}$

\section{Conclusions}

Extrapulmonary thoracic hydatid cysts with extension to chest wall are uncommon. The symptoms are usually due to compression of the surrounding structures by cyst. Serology along with the imaging of the thorax helps to diagnose the disease early. The treatment is primarily surgical supported by antihelmenthic drugs.

\section{References}

[1]. McManus DP, Smyth JD. Hydatidosis: changing concepts in epidemiology and speciation. Parasitol Today. 1986;2:163-68.

[2]. Saidi F. Treatment of echinococcal cysts. In: Nyhus LM, Baker RJ, Sabiston DC, editors. Mastery of surgery. 2nd ed. London: Little, Brown and Company; 1992. p. 818-37.

[3]. Barrett NR. Surgical treatment of the hydatid cyst of the lung. Thorax. 1947;2:21.

[4]. Harlaftis NN, Altreas HA, Panagiotis SN. Hydatid disease of the lung. In: Shields TW, LoCicerco J, Ponn RB, Rusch VW, editors. General Thoracic Surgery. 6th Ed. Philadelphia: Lippincott Williams\& Wilkins, P.1298.

[5]. Ozvaran MK, Ersoy Y, Uskul B, et al. Pleural complications of pulmonary hydatid disease. Respirology. 2004;9:115-19.

[6]. Kabiri el-H, Caidi M, al Aziz S, el Maslout A, Benosman A. Surgical treatment of hydatidothorax. Series of 79 cases. Acta Chir Belg. 2003;103:40104.

[7]. Saksouk FA, Fahl MH, Rizk GK. Computed tomography of pulmonary hydatid disease. J Comput Assist Tomogr. 1986;10:226-32.

[8]. Gouliamos AD, Kalovidouris A, Papailiou J, Vlahos L, Papavasiliou C. CT appearance of pulmonary hydatid disease. Chest. 1991;100:1578-81.

[9]. Kurul IC, Topcu S, Altinok T, et al. One-stage operation for hydatid disease of lung and liver: principles of treatment. J Thorac Cardiovasc Surg. 2002; 124:1212-15.

[10]. Boubia S, Kafih M, Ridai M, Zerouali N. Long-term prognosis of

[11]. hydatid lung cyst treated by video-assisted thoracic surgery. Rev Pneumol Clin. 2005;61:298-300.

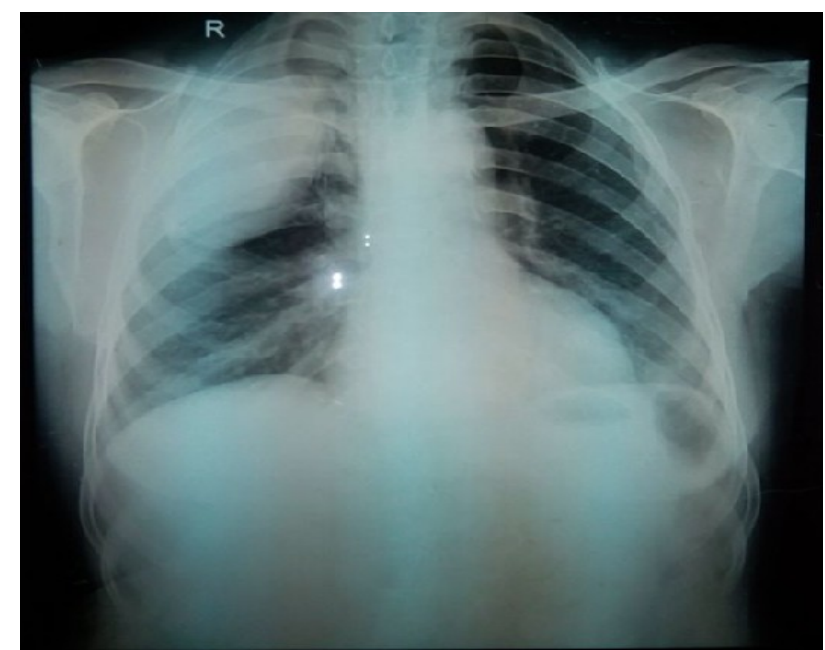

Figure 1. chest $\mathrm{x}$ ray showing opacity in right lung upper and middle zone, that was the hydatid cyst extending out of the thoracic cage 


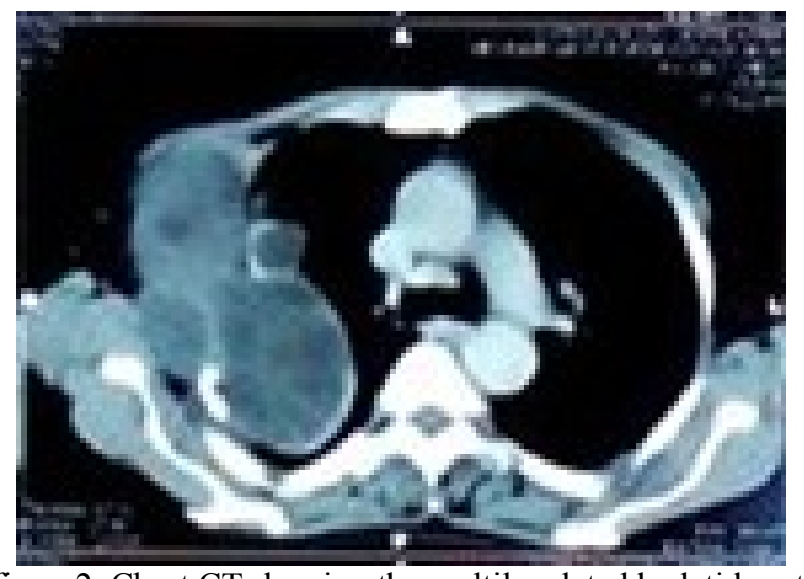

figure2. Chest CT showing the multiloculated hydatid cyst

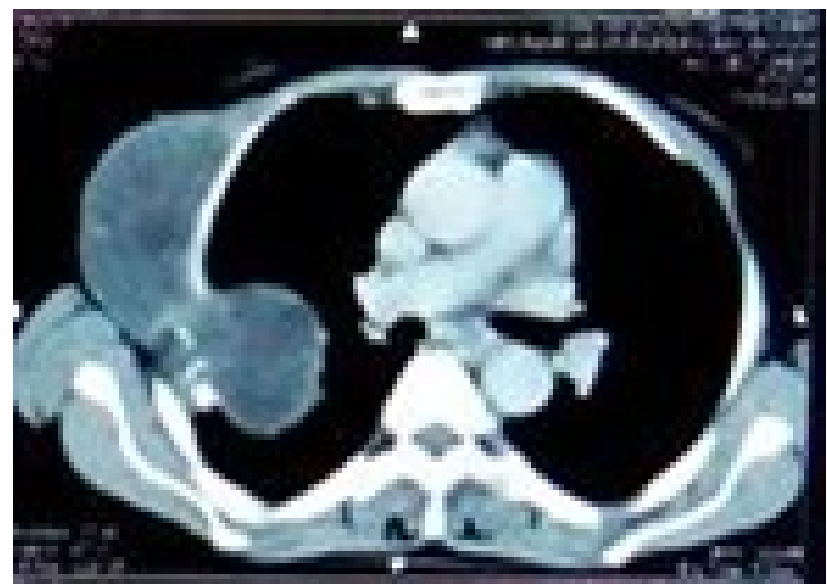

Figure 3. Chest CT showing extrathoraacic extension of the hydatid cyst. This cyst was extrapulmonary, only abutting the lung parenchyma, not invading the lung. 